The Clinical Journal of Pain Publish Ahead of Print

DOI:10.1097/AJP.0000000000000359

The association between chronic pain and cardiac disease: a cross-sectional

\title{
population study
}

$\begin{array}{ll}\begin{array}{l}\text { 1. Author: } \\ \text { Affiliation: } \\ \text { Highest degree: }\end{array} & \begin{array}{l}\text { Dr Alan Fayaz } \\ \text { Imperial College London } \\ \text { MA MBBS MRCP FRCA }\end{array} \\ \begin{array}{ll}\text { 2. Author: } \\ \text { Affiliation: }\end{array} & \begin{array}{l}\text { Ms Hilary C Watt } \\ \text { Imperial College London }\end{array} \\ \text { 3. Author: } & \text { MA CStat } \\ \begin{array}{l}\text { Affiliation: } \\ \text { Highest degree: }\end{array} & \text { Professor Richard M Langford } \\ \text { 4. Author: } & \text { MBBS FRCA FFPMRCA } \\ \text { Affiliation: } & \text { Sir Liam J Donaldson } \\ \text { Highest degree: } & \text { Imperial College London } \\ & \text { MBBS FRCS FMedSci }\end{array}$

Corresponding Author:

Name: $\quad$ Dr Alan Fayaz

Department: $\quad$ Surgery and Cancer

Institution: Imperial College London

Mailing address: $\quad$ Flat B, 2 Fordham Street, London E1 1HS

Phone: $\quad 07884003244$

Fax: $\quad$ None

Email: $\quad$ alanfayaz@gmail.com

The authors declare no conflict of interest.

Funding: No external funding was obtained for this study

Ethics approval: Not required for our secondary analysis, ethical approval for the original survey was obtained from the Oxford A Research Ethics Committee (reference number 10/H0604/56). 


\section{Abstract}

Objectives: Chronic pain may increase the risk of cardiac disease, but the extent to which confounding variables account for this association has yet to be satisfactorily established. This study aims to examine the possibility of an independent association between these two variables.

Methods: We applied logistic regression analysis to data from 8596 adults surveyed in a population study of the health of the population of England. The association between cardiac disease (angina and/or myocardial infarction) and chronic pain (pain lasting greater than three months) was explored, taking account of 10 potentially confounding variables including the regular use of non-steroidal anti-inflammatory drugs.

Results: Participants reporting chronic pain $(n=3023)$ were more likely to experience cardiac disease than those without pain: odds ratio (OR) $1.55,95 \%$ confidence interval (CI) 1.15-2.07. Subsets of participants fulfilling various criteria for highintensity chronic pain demonstrated stronger associations with cardiac disease suggesting a 'dose-response' element to the relationship: chronic widespread pain OR 3.3 (95\% CI 1.42-7.68); higher-disability chronic pain OR 2.35 (95\% CI 1.71-3.23); higher average chronic pain score OR 1.95 (95\% CI 1.40-2.71). Adjustment for regular prescription of non-steroidal anti-inflammatory drugs did not reduce the association of chronic pain with cardiac disease.

Discussion: Patients reporting chronic pain, in particular those most severely affected, may be at significantly increased risk of cardiac disease. Future studies should focus on determining whether reducing the impact of chronic pain can improve cardiac health.

Keywords: Chronic pain; cardiac disease; cardiovascular disease; angina; myocardial ischemic 


\section{Introduction}

A late $20^{\text {th }}$ Century study reporting that farmers with a history of back pain had an almost five-times greater risk of death from ischemic heart disease than those without pain raised interest in the possibility of an association between chronic pain and cardiovascular disease ${ }^{1}$. A more recent study, using data from a large population survey in England, demonstrated a significantly higher prevalence of cardiac disease in adults (aged 65 and over) who also reported chronic pain ${ }^{2}$. This study was limited by the use of surrogates for chronic pain, derived by combining a diagnosis of longterm musculoskeletal conditions with self-reported moderate or severe pain on the day of the survey. While it may not be possible to establish the directionality of an association based on data from cross-sectional studies, there is additional evidence from longitudinal studies suggesting chronic pain as precursor of cardiovascular morbidity ${ }^{3-7}$. Further support for a link between these variables comes from research focusing on pathogenesis. For example, atherosclerosis of the lumbar arteries has been shown to be the forbearer of lower back pain ${ }^{8}$, whilst widespread chronic pain has been implicated in alterations of endothelial function ${ }^{9}{ }^{10}$, hypothalamo-pituitary axis ${ }^{11}$ and autonomic nervous system functioning ${ }^{12-15}$.

Some authors have sought to validate a causal relationship between chronic pain and cardiovascular disease by demonstrating a dose-response effect. In 2000, Cote and colleagues reported that the presence of high-grade chronic neck pain, defined according to 'Grading the Severity of Chronic Pain' questionnaire, was more likely to be associated with cardiovascular conditions moderately or severely impacting health than either intermediate grade chronic pain or low grade chronic pain ${ }^{16}$. Other authors have shown that the number of pain sites may be relevant to the degree of cardiovascular morbidity by comparing outcomes amongst cohorts of patients 
reporting chronic widespread pain ( $>4$ body areas, including axis, upper and lower body), with those reporting only chronic regional pain ${ }^{17}{ }^{18}$. Claims that the risk of cardiovascular disease is proportional to the duration, severity or distribution of chronic pain need to be balanced against the understanding that these studies were entirely based on observational data, with little consistency in the terminology used to define pain symptoms and/or cardiovascular indices. The ability to establish causality has also been hampered by the failure to comprehensively address potentially confounding variables, in particular the regular use of non-steroidal anti-inflammatory drugs (NSAIDS) that have well-publicized effects on cardiovascular health ${ }^{19}$. In this study we have used national data, collected as part of the Health Survey for England (HSE) to explore the hypothesis that chronic pain is independently associated with cardiac disease and that this augmented risk is proportional to the intensity of pain symptoms.

\section{Methods}

Study design: The Health Survey for England is an annual survey collecting information on various aspects of physical health, lifestyle behaviors, social care and mental health from a representative sample of the population of England ${ }^{20}$. The survey was first instructed in 1991, and the $21^{\text {st }}$ chapter (collected in 2011) is the first to include data specifically about chronic pain symptoms. These data are gathered through interviews with respondents, randomly selected from post-code allocated sampling units across the country; objective measures of health such as height, weight and blood pressure are then recorded alongside pre-specified demographics relating to health and social care. Ethical approval for the 2011 survey was obtained from the Oxford A Research Ethics Committee (reference number 10/H0604/56). 
Study Population: Participants were approached at 8992 private households, selected through a process of stratified sampling from 562 geographical sampling units, in order to achieve a nationally representative sample of the English population. A total of 10,617 (8,610 adults) participants were interviewed, achieving a household response rate of $66 \%$. From this cohort 5,715 participants also had a nurse visit allowing further questioning, collection of various anthropomorphic measurements and, where appropriate, blood and salivary samples. Quality control methods to minimize bias in data collection included recall and review of data from both interviews and nurse visits, in approximately $10 \%$ of productive households. Dependent variables: Participants were considered to have cardiac disease if they responded 'Yes' to either of the following questions: (i) "Were you told by a doctor that you had Angina?" (ii) "Were you told by a doctor that you had a Heart Attack (including myocardial infarction or coronary thrombosis)?" A supplementary variable ("cardiac last year") was generated from responses to the same questions, which restricted the outcome to cardiac diagnoses given by a doctor in the year leading up to the survey (albeit not necessarily given for the first time in this preceding year).

Independent variables: Participants were considered to fulfill the criteria for chronic pain if they responded "Yes" to both of the following questions: (i) "Are you currently troubled by pain or discomfort, either all the time or on and off?" (ii) "Have you had this pain or discomfort for more than 3 months?"

Pain disability grade was assessed at interviews using responses to the 'Grading the severity of Chronic Pain Scale' (GSCP), a validated bi-dimensional measure of chronic pain severity, integrating pain intensity with pain-specific disability ${ }^{21} 22$. For the purposes of the statistical analysis grades III and IV were collectively used to 
represent higher-disability chronic pain, while grades I and II were grouped to represent lower-disability chronic pain, as has been done previously in studies addressing cardiovascular outcomes in chronic pain patients ${ }^{1623}$. Pain score severity was taken as an average of participants' current pain score (ranging from 0-10), worst pain score in previous six-months and average pain score in the previous six months. A mean score of 5 or above represented 'higher average chronic pain score' ${ }^{21}$. Pain distribution was classified according to the number of body sites in which chronic pain was reported; participants were offered up to seven body locations including back, neck/shoulder, head/face/dental, stomach/abdominal, limbs, chest or 'other'. Participants reporting chronic pain in four or more distinct body areas were considered to have 'chronic widespread pain' although we acknowledge this definition is not strictly adherent to the American College of Rheumatologists standard ${ }^{24}$. In order to prevent bias from Angina being categorized as chronic pain in the chest area, data from all participants reporting chronic pain in the chest area were excluded from the statistical analysis.

Confounding variables: Age, gender and Income were obtained directly from the core survey questions. The latter was used as a measure of social class, calculated by applying a McClement score to each household (integrating number, age and relationships of adults and children in household) and dividing the total household income by this score. Subjects were grouped into the following quintiles: $<£ 11,676.65$, $£ 11,676.66-£ 19,117.65, £ 19,117.66-£ 27,704.92, £ 27,704.93-£ 47,794.11$, and $>£ 47,794.12$. The effect of smoking was accounted for by dividing subjects into one of three groups; a) never-regular smokers, b) ex-regular smokers or c) current smokers. Body mass index was derived from validated height and weight measurements and participants were separated into quintiles: $<18.5,18.5-24.9,25-$ 
29.9, 30-39.9 and >40. Participants were classified as hypertensive or diabetic if they reported ever receiving these diagnoses directly from a physician. Anxiety and depression were gauged as part of the general health questionnaire with subjects selfreporting as 'not anxious or depressed', 'moderately anxious or depressed' or 'extremely anxious or depressed'. Regular use of NSAIDS was included if the participant had a regular prescription for any drug coded under section 10.01.01 in the British National Formulary, allowing us to differentiate between NSAIDS taken for analgesic purposes and those taken for cardiovascular disease (e.g. Aspirin).

Statistical analysis: All data was processed using STATA SE (version 13). Serial logistic regression analyses were performed addressing the association between cardiac disease and chronic pain, chronic pain distribution, chronic pain disability, and average chronic pain score. The process was then repeated using 'cardiac last year' as the dependent variable. The regression initially included the full complement of confounding variables; non-significant variables were subsequently removed in a step-wise fashion in order to generate our final models. Removing non-significant confounding variables allowed for a greater sample size to be included into the final analyses, since there was missing data for some variables. To this effect BMI and regular NSAIDS were removed from all regression models, anxiety and depression were removed from models analyzing cardiac disease by chronic pain distribution and by chronic pain disability, smoking was removed from all models using cardiac disease in the last year as the dependent variable, and diabetes from the regression model analyzing cardiac disease in the last year against chronic pain disability.

\section{Results}

The characteristics of the study population are presented in Table 1 and Table 2. In total 8610 adults participated in the survey; completed data for question on cardiac 
disease and chronic pain prevalence were available from 8596 participants (male $=$ 3815 , female $=4781)$. The median age of survey respondents with completed data was 49 years.

The prevalence of cardiac disease was $5.5 \%(n=471)$. Just over a third of those with cardiac disease $(n=164)$ were diagnosed in the year leading up to the survey. In both instances male participants reported cardiac disease more frequently than did female participants. Over $35 \%$ of respondents $(n=3023)$ reported chronic pain symptoms; chronic pain symptoms were more common in female participants than in male participants (38\% vs. $33 \%)$.

Cardiac disease (angina or myocardial infarction) occurred more frequently amongst participants reporting chronic pain, with an odds ratio (OR) of 1.87 (95\% confidence intervals [CI] 1.51-2.34), after adjusting for the non-modifiable risk factors age and gender. Table 3 shows the results of a logistic regression analysis in which the association between chronic pain and cardiac disease was tested alongside the full complement of modifiable and non-modifiable confounding variables. Body mass index and NSAIDS were not independently associated with cardiac disease and were removed from the final model. In fact, the estimated OR for cardiac disease amongst users of NSAIDS was always 1.00 or less than 1.00 in all models of risk factors for cardiac disease including chronic pain or chronic pain by severity and other confounding variables. The use of NSAIDS was therefore not adjusted for in the results shown in Table 4 and Table 5, which report OR and CI adjusted for only the statistically significant confounding factors. They show that those with chronic pain are more likely to report cardiac disease, with OR 1.55 (95\% CI 1.15-2.07). The odds of cardiac disease in the presence of chronic pain was much higher when cardiac disease was restricted to the final year of the study, OR 3.20 (95\% CI 1.65-6.18), with 
a very similar result, OR 2.87 (95\%CI 1.45-5.67) when adjusting for all potential confounding variables.

A sub-set (71 people) of those who had reported chronic pain experienced it in four or more distinct body areas (chronic widespread pain), approximating to $2.3 \%$ of the chronic pain cohort (Table 1). There were significantly fewer male participants reporting chronic pain, who met our criteria for chronic widespread pain than females (1.2\% vs. $3.1 \%)$. Cardiac disease was significantly more common in participants reporting chronic regional pain (1-3 sites) and those reporting chronic widespread pain, when compared to participants with no chronic pain. However, the odds of cardiac disease was more than doubled in the chronic widespread pain group as compared to the chronic regional pain group OR 3.30 (95\% CI 1.42-7.68) vs. OR 1.45 (95\% CI 1.12-1.89), respectively. Similar proportions were evident in the "cardiaclast-year" model (Table 5).

Almost twice as many chronic pain sufferers were classified as having low-disability chronic pain (GSCP Grades I and II) than high-disability chronic pain (GSCP grades III and IV). Only high-disability pain was statistically significantly associated with cardiac disease after correction for confounding variables OR 2.35 (95\% CI 1.71 3.23) and OR 6.70 (95\% CI 3.26-13.75) for cardiac disease and cardiac disease in the last year, respectively.

Just over half of the participants with chronic pain reported average chronic pain scores greater than or equal to 5/10. Again, a statistically significant association with cardiac disease was only apparent in the cohort reporting higher average chronic pain scores. The odds for this association were more than doubled when outcomes were restricted to the final year of the survey OR 4.13 (95\% CI 2.05-8.33) vs. OR 1.95 (95\% CI 1.40-2.71). 
Participants excluded from the statistical model accounting for the full complement of confounding variables were marginally older, wealthier, and more likely to be prescribed NSAIDS but less often hypertensive and diabetic then were included participants. With progressive removal on non-significant variables the proportion of 'excluded' participants were reduced; consequently the study population more closely represented the survey population.

\section{Discussion}

The aim of our study was to explore the hypothesis that chronic pain may be independently associated with cardiac disease, and to qualify the strength of this association by searching for a dose-response relationship between the two variables.

We have demonstrated that participants reporting chronic pain symptoms were 55\% more likely to experience cardiac disease than those not reporting chronic pain, after adjustment for confounding variables. In our study we used three different indices for pain intensity: chronic pain distribution, chronic pain disability and average chronic pain score. Our data indicate that cardiac risk increases markedly in-line with chronic pain intensity, irrespective of the measure used.

Our results are consistent with published studies citing statistically significant increases in cardio-vascular morbidity, ranging from $18 \%$ to $83 \%{ }^{25-27}$, that are also most pronounced in populations with higher-intensity chronic pain ${ }^{17}{ }^{18}$. However, in previous studies confounding variables were not comprehensively accounted for in the statistical models used. We have adjusted for a wide range of potentially confounding cardiovascular risk factors including: age, gender, socio-economic status, body mass index, diabetes, hypertension, smoking, anxiety, depression and regular use of non-steroidal anti-inflammatory drugs (NSAIDS). To our knowledge this is 
the first study to account for the use of these drugs as a confounding variable in the association between chronic pain and cardiovascular disease.

We found that the regular use of NSAIDS was independently associated with both chronic pain and cardiac disease. However, it was not a statistical confounder in the association between chronic pain and cardiac disease (Table 3). Interestingly, when logistic regression analysis was used to quantify the association between NSAIDS use and the presence of cardiac disease, adding chronic pain (as a potential confounder) to the model does in fact remove statistical significance (results not shown). While it would be simplistic to surmise that the cardiac risk attributable to regular use of NSAIDS could be explained entirely by co-existing chronic pain, our data highlight the complex interplay between these three factors in clinical practice; reaffirming the need to carefully balance the overall cardiac risk against the potential analgesic benefit NSAIDS could provide in chronic pain patients.

Strengths and limitations: Our study is based on observational data from a national survey. Self-reporting of chronic physical conditions has previously been shown to demonstrate moderate to high agreement with data from medical records ${ }^{28}$, and we feel the large, nationally representative, sample size, as well as the quality control measures used by the Health Survey for England to validate the data, add robustness to our analysis. However, an important limitation of the present study is that anxiety and depression were not measured using well-validated assessments tools. Instead, participants were asked whether they feel depressed or anxious, moderately depressed or anxious, or severely depressed or anxious, and we cannot really know if participants were really having depressive symptoms or just showing some distress. There was also no specific assessment of post-traumatic stress disorder that has been linked with both chronic pain and cardiovascular disease ${ }^{2930}$, and would have ideally 
been adjusted for as a confounding variable in the statistical analysis. In some instances the questioning format used in the survey was more restrictive than we would have liked, and the coding of prescription drugs did not allow us to identify the specific anti-depressant medicines or opioid analgesics used by participants, some of which may be associated with an increased risk of cardiovascular events ${ }^{31} 32$. Furthermore, the data on medication usage were limited to prescription drugs, therefore we were not able to account for over-the-counter use of NSAIDS, nor could we identify the dose or quantity of the drugs actually taken by study participants. As the data source is cross-sectional, we are limited in our ability to attribute directionality. For example it is possible that in some instances cardiac disease preceded or perhaps even predisposed to chronic pain, as would be the case with chronic chest pain. In order to address this issue we have excluded participants who reported chronic pain symptoms in the chest area from our analysis. Additionally we ran parallel regression analyses, restricting the cardiovascular outcome to the last year of the survey. The demonstration that all our outcomes remained statistically significant was re-assuring. In fact in all instances the likelihood of cardiac disease actually increased in the restricted outcome set, with a greater than 7-fold increased risk in participants reporting chronic widespread pain than those without pain. Population estimates from the prevalence of chronic pain in the United Kingdom range from $35 \%$ to $51.3 \%{ }^{33} 34$, with up to $16.5 \%$ of the general population reporting chronic widespread pain ${ }^{33}$. Similar figures have been quoted from studies looking at the prevalence of severe chronic pain in European countries ${ }^{35}$. Extrapolation of the results of our study across these populations highlights a fairly underpublicized public health concern. While we are unable to establish causality in the absence of further support from longitudinal studies, we can acknowledge that chronic pain populations, 
in particular those most severely affected, are likely to benefit from regular assessment of cardiac risk, and targeted measures to reduce this risk.

In conclusion, this study has found an increased prevalence of cardiovascular disease amongst survey participants reporting chronic pain, an association that retains statistical significance even after corrections for potentially confounding cardiovascular risk factors. These results support the notion that chronic pain may be an independent and modifiable risk factor for cardiac disease, and aid in highlighting a hitherto underpublicized public health concern. Future work needs to address the possibility of modifying the impact of chronic pain on cardiovascular morbidity and mortality through improved pain control and reduction of symptom intensity.

Acknowledgements: All authors included on a paper fulfil the criteria of authorship. In addition, there is no one else who fulfils the criteria but has not been included as an author.

Contributions: AF designed the study using data obtained from the National Centre for Social Research, wrote the statistical analysis plan, cleaned and analysed the data, drafted and revised the paper. He is the guarantor. HW assisted with the statistical design, statistical analysis and revisions to the draft paper. RL and LD contributed to the design of the study and revised the draft paper.

\section{References}

1. Penttinen J. Back pain and risk of fatal ischaemic heart disease: 13 year follow up of Finnish farmers. BMJ 1994;309(6964):1267-8.

2. Ryan CG, McDonough S, Kirwan JP, et al. An investigation of association between chronic musculoskeletal pain and cardiovascular disease in the Health Survey for England (2008). European Journal of Pain (United Kingdom) 2014;18(5):740-50.

3. Chen HM, Lin CC, Kang CS, et al. Bladder pain syndrome/interstitial cystitis increase the risk of coronary heart disease. Neurourology \& Urodynamics 2014;33(5):511-5.

4. Lindgren H, Bergman S. Chronic musculoskeletal pain predicted hospitalisation due to serious medical conditions in a 10 year follow up study. BMC Musculoskeletal Disorders 2010;11:127. 
5. Mease PJ, Duh MS, Vekeman F, et al. Evaluation of cardiovascular diseases (CVDs) risk for patients with fibromyalgia syndrome in the United States. Pharmacoepidemiology and Drug Safety 2010;19:S284-S85.

6. Tsai PS, Fan YC, Huang CJ. Fibromyalgia is associated with coronary heart disease: A population-based cohort study. Regional Anesthesia and Pain Medicine 2015;40(1):37-42.

7. Zhu K, Devine A, Dick IM, et al. Association of back pain frequency with mortality, coronary heart events, mobility, and quality of life in elderly women. Spine 2007;32(18):2012-8.

8. Kauppila LI. Atherosclerosis and disc degeneration/low-back pain--a systematic review. European Journal of Vascular \& Endovascular Surgery 2009;37(6):661-70.

9. Lee JH, Cho KI, Kim SM, et al. Arterial stiffness in female patients with fibromyalgia and its relationship to chronic emotional and physical stress. Sunhwangi 2011;41(10):596-602.

10. Cho KI, Lee JH, Kim SM, et al. Assessment of endothelial function in patients with fibromyalgia-cardiac ultrasound study. Clinical Rheumatology 2011;30(5):647-54.

11. Tanriverdi F, Karaca Z, Unluhizarci K, et al. The hypothalamo-pituitary-adrenal axis in chronic fatigue syndrome and fibromyalgia syndrome. Stress 2007;10(1):13-25.

12. Martinez-Lavin M. Biology and therapy of fibromyalgia. Stress, the stress response system, and fibromyalgia. Arthritis Res Ther 2007;9(4):216.

13. Reyes del Paso GA, Garrido S, Pulgar A, et al. Autonomic cardiovascular control and responses to experimental pain stimulation in fibromyalgia syndrome. Journal of Psychosomatic Research 2011;70(2):125-34.

14. da Cunha Ribeiro RP, Roschel H, Artioli GG, et al. Cardiac autonomic impairment and chronotropic incompetence in fibromyalgia. Arthritis Research \& Therapy 2011;13(6):R190.

15. Furlan R, Colombo S, Perego F, et al. Abnormalities of cardiovascular neural control and reduced orthostatic tolerance in patients with primary fibromyalgia. The Journal of rheumatology 2005;32(9):1787-93.

16. Cote P, Cassidy JD, Carroll L. The factors associated with neck pain and its related disability in the Saskatchewan population. Spine 2000;25(9):1109-17.

17. Andersson H. Increased mortality among individuals with chronic widespread pain relates to lifestyle factors: A prospective population-based study. Disability and Rehabilitation: An International, Multidisciplinary Journal 2009;31(24):1980-87.

18. Kadam UT, Thomas E, Croft PR. Is chronic widespread pain a predictor of allcause morbidity? A 3 year prospective population based study in family practice. J Rheumatol 2005;32(7):1341-8.

19. Bhala N, Emberson J, Merhi A, et al. Vascular and upper gastrointestinal effects of non-steroidal anti-inflammatory drugs: meta-analyses of individual participant data from randomised trials. Lancet 2013;382(9894):769-79.

20. Craig R, Mindell J. Health Survey for England 2011. Volume2: Methods and documentation. 21 ed: Health and Social Care Information Centre, 2012. http://www.ic.nhs.uk/pubs/hse11report.

21. Von Korff M, Ormel J, Keefe FJ, et al. Grading the severity of chronic pain. Pain 1992;50(2):133-49. 
22. Smith BHa, Penny KIb, Purves AMa, et al. The Chronic Pain Grade questionnaire: validation and reliability in postal research. Pain 1997;71(2):141-47.

23. Torrance N, Elliott AM, Lee AJ, et al. Severe chronic pain is associated with increased 10 year mortality. A cohort record linkage study. European journal of pain (London, England) 2010;14(4):380-6.

24. Wolfe F, Smythe HA, Yunus MB, et al. The American College of Rheumatology 1990 Criteria for the Classification of Fibromyalgia. Report of the Multicenter Criteria Committee. Arthritis Rheum 1990;33(2):160-72.

25. Ryan CG, McDonough S, Kirwan JP, et al. An investigation of association between chronic musculoskeletal pain and cardiovascular disease in the Health Survey for England (2008). European journal of pain (London, England) 2013.

26. Lindgren H, Bergman S. Chronic musculoskeletal pain predicted hospitalisation due to serious medical conditions in a 10 year follow up study. BMC Musculoskelet Disord 2010;11:127.

27. Makela M, Heliovaara M, Sievers K, et al. Prevalence, determinants, and consequences of chronic neck pain in Finland. Am J Epidemiol 1991;134(11):1356-67.

28. Evaluation of National Health Interview Survey diagnostic reporting. Vital and health statistics Series 2, Data evaluation and methods research 1994(120):1116.

29. Coughlin SS. Post-traumatic Stress Disorder and Cardiovascular Disease. The open cardiovascular medicine journal 2011;5:164-70.

30. Palyo SA, Beck JG. Post-traumatic stress disorder symptoms, pain, and perceived life control: Associations with psychosocial and physical functioning. Pain 2005;117(1-2):121-7.

31. Hamer M, Batty GD, Seldenrijk A, et al. Antidepressant medication use and future risk of cardiovascular disease: the Scottish Health Survey. Eur Heart J 2011;32(4):437-42.

32. Khodneva Y, Muntner P, Kertesz S, et al. Prescription Opioid Use and Risk of Coronary Heart Disease, Stroke, and Cardiovascular Death among Adults from a Prospective Cohort (REGARDS Study). Pain Med 2015.

33. Beasley M, Macfarlane GJ. Chronic widespread pain versus multi-site pain: Does the distribution matter? Arthritis and Rheumatology 2014;66:S908-S09.

34. Croft P, Rigby AS, Boswell R, et al. The prevalence of chronic widespread pain in the general population. Journal of Rheumatology 1993;20(4):710-13.

35. Breivik H, Collett B, Ventafridda V, et al. Survey of chronic pain in Europe: prevalence, impact on daily life, and treatment. European journal of pain (London, England) 2006;10(4):287-333.

TABLE 1: PARTICIPANT DEMOGRAPHICS BY PAIN STATUS AND SEVERITY

\begin{tabular}{|c|c|c|c|c|c|c|}
\hline Variable & "n" & $\begin{array}{c}\text { "n"=male } \\
(\%)\end{array}$ & Age mean (SD) & Age Range & $\begin{array}{c}\text { "n" with Cardiac } \\
(\%)\end{array}$ & $\begin{array}{c}\text { "n" with } \\
\text { Cardiac last } \\
\text { year }^{\S}(\%)\end{array}$ \\
\hline Total survey adults & 8610 & $3822(44)$ & $49.64(18.7)$ & $16-100$ & $471(5.5)$ & $164(1.9)$ \\
\hline \multicolumn{7}{|l|}{ Cardiac disease } \\
\hline No & 8136 & $3537(43)$ & $48(18.3)$ & $16-100$ & - & - \\
\hline Yes & 471 & $283(60)$ & $70(12.1)$ & $27-96$ & - & - \\
\hline Yes (last year only) ( $^{\S}$ & 164 & $97(59)$ & $70.1(11.9)$ & $31-94$ & - & - \\
\hline \multicolumn{7}{|l|}{ Chronic pain } \\
\hline No & 5397 & $2510(46)$ & $45.5(18.3)$ & $16-100$ & $152(2.8)$ & $27(0.5)$ \\
\hline Yes & 3023 & $1225(41)$ & $56.6(17.2)$ & $16-97$ & $249(8.2)$ & $87(2.9)$ \\
\hline
\end{tabular}




\begin{tabular}{|c|c|c|c|c|c|c|}
\hline \multicolumn{7}{|l|}{ Pain distribution } \\
\hline $\begin{array}{l}\text { Regional chronic pain } \\
\text { (1-3 sites) }\end{array}$ & 2950 & $1208(41)$ & $56.6(17.3)$ & $16-97$ & $238(8)$ & $81(2.8)$ \\
\hline $\begin{array}{l}\text { Widespread chronic } \\
\text { pain (>3 sites) }\end{array}$ & 71 & $15(21)$ & $56.5(16.6)$ & $19-87$ & $11(15)$ & $6(8.7)$ \\
\hline \multicolumn{7}{|l|}{ Pain disability* } \\
\hline $\begin{array}{l}\text { Low disability (grade I- } \\
\text { II) }\end{array}$ & 2081 & $863(41)$ & $55.1(17.1)$ & $16-97$ & $122(5.9)$ & $38(1.8)$ \\
\hline $\begin{array}{l}\text { High disability (grade } \\
\text { III-IV) }\end{array}$ & 913 & $346(37)$ & $59.8(17.0)$ & $16-96$ & $125(13.7)$ & $48(5.3)$ \\
\hline \multicolumn{7}{|l|}{ Pain score severity } \\
\hline $\begin{array}{l}\text { Low (average pain score } \\
\text { 1-4) }\end{array}$ & 1416 & $652(46)$ & $54.9(17.4)$ & $16-97$ & $75(5.3)$ & $21(1.5)$ \\
\hline $\begin{array}{l}\text { High (average pain } \\
\text { score }>4 \text { ) }\end{array}$ & 1537 & $552(35)$ & $58(17.0)$ & $16-95$ & $170(10.8)$ & $64(4.1)$ \\
\hline
\end{tabular}

$n$ (number), SD (standard deviation)

${ }^{\S}$ A subgroup analysis was performed on subjects who were diagnosed with cardiac disease in the year leading up to the survey

"Pain disability was derived from the 'Chronic pain grade scale' Questionnaire

${ }^{\dagger}$ Numbers in complementary categories may not add up to total number of patients because of missing data

TABLE 2: DISTRIBUTION OF CONFOUNDING VARIABLES BY CHRONIC PAIN STATUS

\begin{tabular}{|c|c|c|c|c|}
\hline & \multicolumn{2}{|c|}{ Chronic Pain Status } & \multicolumn{2}{|c|}{ Cardiac Disease Status } \\
\hline & $\begin{array}{c}\text { Yes }(n=3023) \\
n(\%)\end{array}$ & $\begin{array}{c}\text { No }(n=5397) \\
n(\%)\end{array}$ & $\begin{array}{c}\text { Yes }(n=471) \\
n(\%)\end{array}$ & $\begin{array}{c}\text { No }(n=8136 \\
n(\%)\end{array}$ \\
\hline \multicolumn{5}{|l|}{ Gender } \\
\hline Male & $2510(46)$ & $1225(41)$ & $283(60)$ & $3537(43)$ \\
\hline Female & $2887(54)$ & $1798(59)$ & $188(40)$ & $4599(57)$ \\
\hline \multicolumn{5}{|l|}{ Income } \\
\hline$>£ 47794.12$ & $1011(24)$ & 407 (17) & $77(22)$ & $1124(17)$ \\
\hline$>£ 27704.92<=£ 47794.12$ & $953(23)$ & $442(18)$ & $115(33)$ & $1303(20)$ \\
\hline$>£ 19117.65<=£ 27704.92$ & $798(19)$ & $525(21)$ & $89(26)$ & $1268(20)$ \\
\hline$>£ 11676.65<=£ 19117.65$ & $798(19)$ & $577(24)$ & $38(11)$ & $1369(21)$ \\
\hline$<=£ 11676.65$ & $662(16)$ & $496(20)$ & $26(8)$ & $1402(22)$ \\
\hline \multicolumn{5}{|l|}{ Age } \\
\hline 16-29 & $1212(22)$ & $216(7)$ & $1(0)$ & $1444(18)$ \\
\hline 30-39 & $1048(19)$ & 319 (11) & $4(1)$ & $1379(17)$ \\
\hline $40-49$ & $1045(19)$ & $533(18)$ & $23(5)$ & $1580(19)$ \\
\hline $50-59$ & $735(14)$ & $555(18)$ & $55(12)$ & $1276(16)$ \\
\hline $60-69$ & $707(13)$ & $640(21)$ & $116(25)$ & $1267(16)$ \\
\hline 70-79 & $434(8)$ & $454(15)$ & $159(34)$ & $766(9)$ \\
\hline$>80$ & $216(4)$ & $306(10)$ & $113(24)$ & $424(5)$ \\
\hline \multicolumn{5}{|l|}{ Body Mass Index } \\
\hline$<18.5$ & $80(2)$ & & $4(1)$ & $107(2)$ \\
\hline $18.5-24.9$ & $1728(39)$ & $673(28)$ & $64(18)$ & $2375(36)$ \\
\hline $25-29.9$ & $1692(38)$ & $930(38)$ & $136(39)$ & $2524(38)$ \\
\hline $30-39.9$ & $888(20)$ & $704(29)$ & $136(39)$ & $1505(23)$ \\
\hline$>40$ & $85(2)$ & $96(4)$ & $9(3)$ & $177(3)$ \\
\hline \multicolumn{5}{|l|}{ Smoking history } \\
\hline Never regular & $3015(56)$ & $1378(46)$ & $185(39)$ & $4286(53)$ \\
\hline Ex-regular & $1260(24)$ & $1029(34)$ & $212(45)$ & $2139(27)$ \\
\hline Regular & $1067(20)$ & $601(20)$ & $72(15)$ & $1635(20)$ \\
\hline \multicolumn{5}{|l|}{ Raised blood pressure } \\
\hline Yes & $1116(21)$ & $1149(38)$ & $167(36)$ & $6086(75)$ \\
\hline No & $4278(79)$ & $1872(62)$ & $303(64)$ & $2044(25)$ \\
\hline \multicolumn{5}{|l|}{ Diabetes Mellitus } \\
\hline Yes & $5153(95)$ & $2728(90)$ & $345(73)$ & $7677(95)$ \\
\hline No & $243(5)$ & $290(10)$ & $126(27)$ & $446(5)$ \\
\hline \multicolumn{5}{|l|}{$\begin{array}{l}\text { Self-reported } \\
\text { anxiety/depression }\end{array}$} \\
\hline None & $3815(80)$ & $1681(62)$ & $223(59)$ & $5336(74)$ \\
\hline Moderate & $859(18)$ & $893(5)$ & $132(35)$ & $1691(23)$ \\
\hline Extreme & $76(2)$ & $98(4)$ & $20(5)$ & $172(2)$ \\
\hline \multicolumn{5}{|l|}{ NSAID prescription } \\
\hline Yes & $46(1)$ & $204(7)$ & $452(96)$ & $7895(97)$ \\
\hline No & $5351(99)$ & $2819(93)$ & $19(4)$ & $241(3)$ \\
\hline
\end{tabular}


TABLE 3: CHRONIC PAIN AND CARDIAC DISEASE ADJUSTING FOR ALL CONFOUNDING VARIABLES

\begin{tabular}{|c|c|c|c|}
\hline & OR & p-value & $95 \% \mathrm{CI}$ \\
\hline Chronic pain & 1.45 & 0.02 & $1.06-2.00$ \\
\hline NSAID prescription & 1.00 & 1.00 & $0.53-1.89$ \\
\hline Gender (female) & 0.48 & $<0.001$ & $0.35-0.66$ \\
\hline \multicolumn{4}{|l|}{ Income } \\
\hline$>£ 47794.12$ & 1.00 & - & - \\
\hline$>£ 27704.92<=£ 47794.12$ & 1.23 & 0.51 & $0.66-2.29$ \\
\hline$>£ 19117.65<=£ 27704.92$ & 1.52 & 0.15 & $0.87-2.66$ \\
\hline$>£ 11676.65<=£ 19117.65$ & 1.74 & 0.05 & $1.00-3.03$ \\
\hline$<=£ 11676.65$ & 1.76 & 0.06 & $0.98-3.17$ \\
\hline \multicolumn{4}{|l|}{ Age } \\
\hline 16-29 & 1.00 & - & - \\
\hline 30-39 & 2.78 & 0.38 & $0.29-26.95$ \\
\hline $40-49$ & 6.85 & 0.07 & $0.87-53.96$ \\
\hline 50-59 & 19.11 & 0.004 & $2.56-142.93$ \\
\hline $60-69$ & 42.51 & $<0.001$ & $5.80-311.80$ \\
\hline 70-79 & 76.24 & $<0.001$ & $10.34-526.31$ \\
\hline$>80$ & 92.50 & $<0.001$ & $12.19-701.61$ \\
\hline \multicolumn{4}{|l|}{ BMI } \\
\hline$<18.5$ & 1.00 & - & - \\
\hline 18.5-24.9 & 0.48 & 0.27 & $0.13-1.76$ \\
\hline 25-29.9 & 0.58 & 0.40 & $0.16-2.06$ \\
\hline 30-39.9 & 0.71 & 0.59 & $0.20-2.53$ \\
\hline$>40$ & 0.56 & 0.45 & $0.12-2.56$ \\
\hline \multicolumn{4}{|l|}{ Smoking history } \\
\hline Never regular & 1.00 & - & - \\
\hline Ex-regular & 1.13 & 0.47 & \\
\hline Regular & 1.62 & 0.03 & $1.05-2.52$ \\
\hline Raised blood pressure & 1.77 & $<0.001$ & $1.28-2.43$ \\
\hline Diabetes Mellitus & 1.76 & 0.01 & $1.17-2.63$ \\
\hline \multicolumn{4}{|c|}{ Self-reported anxiety/depression } \\
\hline None & 1.00 & - & \\
\hline Moderate & 1.28 & 0.16 & $0.91-1.79$ \\
\hline Extreme & 1.23 & 0.68 & $0.46-3.27$ \\
\hline
\end{tabular}

OR (odds ratio), se (standard error), CI (confidence intervals), NSAIDS (non-steroidal anti-inflammatory drugs), BMI (body mass index), $n$ (number of participants included in analysis)

TABLE 4: CARDIAC DISEASE AGAINST PAIN STATUS/INTENSITY CORRECTING FOR STATISTICALLY SIGNIFICANT CONFOUNDERS ONLY

\begin{tabular}{|c|c|c|c|}
\hline 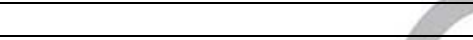 & OR & p-value & $95 \% \mathrm{CI}$ \\
\hline \multicolumn{4}{|l|}{ Chronic pain status } \\
\hline No chronic pain & 1.00 & - & - \\
\hline Chronic pain* & 1.55 & $<0.001$ & $1.15-2.07$ \\
\hline \multicolumn{4}{|l|}{ Chronic pain distribution } \\
\hline No chronic pain & 1.00 & - & - \\
\hline Regional chronic pain (1-3 sites $)^{\dagger}$ & 1.45 & 0.01 & $1.12-1.89$ \\
\hline Widespread chronic pain $(>3 \text { sites })^{\dagger}$ & 3.30 & 0.01 & $1.42-7.68$ \\
\hline \multicolumn{4}{|l|}{ Chronic pain disability } \\
\hline No chronic pain & 1.00 & - & - \\
\hline Low disability (grade I-II) ${ }^{*}$ & 1.11 & 0.48 & $0.82-1.51$ \\
\hline High disability (grade III-IV) & 2.35 & $<0.001$ & $1.71-3.23$ \\
\hline \multicolumn{4}{|l|}{ Chronic pain score severity } \\
\hline No chronic pain & 1.00 & - & - \\
\hline Low (average pain score $1-4)^{\S}$ & 1.09 & 0.65 & $1.75-1.60$ \\
\hline High (average pain score $>4)^{\S}$ & 1.95 & $<0.001$ & $1.40-2.71$ \\
\hline
\end{tabular}

OR (odds ratio), se (standard error), CI (confidence intervals)

*adjusted for gender, income, age, smoking, blood pressure, diabetes, and self reported anxiety/depression

adjusted for gender, income, age, smoking, blood pressure and diabetes

*adjusted for gender, income, age, smoking, blood pressure and diabetes 
TABLE 5: CARDIAC DISEASE RESTRICTED TO THE FINAL YEAR OF THE SURVEY AGAINST PAIN STATUS/INTENSITY CORRECTING FOR STATISTICALLY SIGNIFICANT CONFOUNDERS ONLY

\begin{tabular}{|c|c|c|c|}
\hline & OR & p-value & $95 \% \mathrm{CI}$ \\
\hline \multicolumn{4}{|l|}{ Chronic pain status } \\
\hline No chronic pain & 1.00 & - & - \\
\hline Chronic pain* & 3.20 & 0.001 & $1.65-6.18$ \\
\hline \multicolumn{4}{|l|}{ Chronic pain distribution } \\
\hline No chronic pain & 1.00 & - & - \\
\hline Regional chronic pain (1-3 sites) ${ }^{\dagger}$ & 3.10 & 0.001 & $1.60-6.02$ \\
\hline $\begin{array}{l}\text { Widespread chronic pain }(>3 \\
\text { sites) })^{\dagger}\end{array}$ & 7.11 & 0.003 & $1.92-26.32$ \\
\hline \multicolumn{4}{|l|}{ Chronic pain disability } \\
\hline No chronic pain & 1.00 & - & - \\
\hline Low disability (grade I-II) ${ }^{*}$ & 1.93 & 0.08 & $0.92-4.08$ \\
\hline High disability (grade III-IV) * & 6.70 & $<0.001$ & $3.26-13.75$ \\
\hline \multicolumn{4}{|l|}{ Chronic pain score severity } \\
\hline No chronic pain & 1.00 & - & - \\
\hline Low (average pain score $1-4)^{\S}$ & 2.05 & 0.08 & $0.92-4.56$ \\
\hline High (average pain score $>4)^{\S}$ & 4.13 & $<0.001$ & $2.05-8.33$ \\
\hline
\end{tabular}

OR (odds ratio), se (standard error), CI (confidence intervals)

* adjusted for gender, income, age, blood pressure, diabetes, and self reported anxiety/depression

$\dagger$ adjusted for gender, income, age, blood pressure, diabetes, and self reported anxiety/depression

$\$$ adjusted for gender, income, age, blood pressure, and self reported anxiety/depression 